\title{
Curcumin Enhances Bortezomib Treatment of Myeloma by Inhibiting Heat Shock Protein 90 Expression
}

\author{
Bing-Mu Fang ${ }^{1}$, Jin-Hong Jiang ${ }^{1}$, Xue-Wu Zhang ${ }^{2}$, Jian Fan ${ }^{2}$, Shuang-shuang \\ $\mathrm{Li}^{2}$ and Xiang-Min Tong ${ }^{2 *}$ \\ ${ }^{1}$ The Lishui People's Hospital, Lishui 324000, ${ }^{2}$ Department of Hematology, First Affiliated Hospital, Zhejiang University College \\ of Medicine, Hangzhou, Zhejiang 310003, PR China
}

*For correspondence: Email: tongxiangmin@163.com; Tel/Fax: 86-571-87236628

\begin{abstract}
Purpose: To investigate whether curcumin augments bortezomib-induced apoptosis in myeloma cells (MM1.R line), and to explore the molecular mechanism with regard to heat shock protein 90 (HSP90) expression.

Methods: MTT cell viability assay was used to assess growth inhibition of MM1.R cells at different concentrations of curcumin alone and also combined with $0.01 \mathrm{mM}$ bortezomib. Annexin $V$ and propidium iodide (PI) labeling were used to detect apoptosis. Caspase 3, caspase 9, NF-KB, and HSP 90 protein expression were measured by Western blotting.

Results: Curcumin alone inhibited MM1.R cell growth and increased apoptosis in a concentrationdependent manner. When curcumin was combined with low concentration $(0.01 \mathrm{mM})$ bortezomib, both effects (viability inhibition and apoptosis induction increased $(p<0.05)$, whereas bortezomib alone had no effect $(p>0.05)$. Western blotting revealed that for curcumin and combined treatments, expression of the apoptotic markers, caspase 3 and caspase 9, increased while expression of NF-KB and HSP 90 decreased $(p<0.05)$. Again, low concentration bortezomib alone had no effect, whereas the combined treatment showed the largest effect, thus suggesting that the actions of curcumin and bortezomib are synergistic.

Conclusion: Curcumin increased MM1.R cell sensitivity to bortezomib, which may be due to suppression of NF-KB and HSP90 activity.
\end{abstract}

Keywords: Curcumin, Bortezomib, Myeloma cells, Cell growth, Apoptosis, Heat shock protein 90

Tropical Journal of Pharmaceutical Research is indexed by Science Citation Index (SciSearch), Scopus, International Pharmaceutical Abstract, Chemical Abstracts, Embase, Index Copernicus, EBSCO, African Index Medicus, JournalSeek, Journal Citation Reports/Science Edition, Directory of Open Access Journals (DOAJ), African Journal Online, Bioline International, Open-J-Gate and Pharmacy Abstracts

\section{INTRODUCTION}

Multiple myeloma (MM) is a common hematologic disease, which is caused by proliferation of malignant monoclonal plasma cells in the bone marrow. The expression of heat shock protein 90 (HSP90) in myeloma cells has been shown to be two to ten times that found in normal cells, indicating that HSP90 may play a critical role in promoting tumor cell proliferation and in the progression of MM $[1,2]$. HSPs form a group of proteins whose expression is induced by many stressors such as heat, radiation, hypoxia, and toxins [3]. HSP90 is one of the most active molecular chaperones and it plays a vital role in many physiological and pathological processes. It is extensively involved in cell signal transduction and transcriptional regulation of hormone responses.Despite clinical awareness for more than 150 years, MM is still an incurable disease. Many treatment strategies have been employed, including traditional chemotherapy, 
stem cell transplantation, bortezomib combination programs, and thalidomide programs [4]. Bortezomib is the first proteasome inhibitor to be used in the clinic; it has shown remarkable success in the treatment of hematological malignancies and is regarded as one of the most effective drugs for the treatment of MM [5]. However, it remains necessary to explore new combined treatments to improve the survival and prognosis of patients with MM, particularly on account of bortezomib's adverse effects such as nausea, diarrhea, thrombocytopenia, and peripheral neuropathy [6]. Therefore, we set out to find natural compounds that do not interact with bortezomib, but sensitize tumors to its therapeutic effects.

Curcumin is a phenolic pigment extracted from the rhizome of the turmeric plant (Curcuma longa), a member of the ginger family. It has attracted much interest due to its low toxicity, proven pharmacological safety, and favorable biological activity, which includes lowering of blood fat as well as anti-inflammatory and antitumor effects. Its antitumor effects, both alone and combined with other chemotherapeutics, are widely supported by recent studies, and one of these has shown that curcumin can inhibit the proliferation of malignant plasma cells (myeloma cells) and induce apoptosis [7].

Therefore, we hypothesized that curcumin and bortezomib in combination could have a synergistic effect on myeloma cells. Such a combined treatment could reduce drug resistance and adverse reactions caused by bortezomib, thus improving the quality of life of MM patients. Our hypothesis was examined in vitro by measuring rates of myeloma cell (MM1.R cell line) growth and apoptosis. We also investigated the expression of HSP90 and a number of other signaling proteins to shed light on the mechanism of such effects.

\section{EXPERIMENTAL}

\section{Materials}

Bortezomib was purchased from Millennium Pharmaceuticals Corporation (MA, USA). Curcumin and tetrazolium blue (MTT) were from
Sigma (MO, USA). The Annexin V FITC and apoptosis detection kit (including propidium iodide) was obtained from BD Biosciences (CA, USA). Anti-poly-ADP ribose polymerase (PARP) antibody and horseradish peroxidase (HRP)conjugated anti-mouse and anti-rabbit IgGs were purchased from Cell-signal (USA). RPMI 1640 media and fetal bovine serum (FBS) were from Gibco (CA, USA). Murine antibodies for caspases 3 and 9, NF-kB, and HSP90 were obtained from Santa Cruz (CA, USA).

\section{Cell culture and experimental groups}

Dex-resistant human multiple myeloma cell lines (MM.1R), which were kindly provided by Dr. Steven Rosen of Northwest University (Illinois, US), was cultured in RPMI 1640 culture medium containing $10 \%$ FBS in an atmosphere of $5 \%$ $\mathrm{CO} 2$ at $37^{\circ} \mathrm{C}$. Every $3-4$ days the medium was replaced and the cells were subcultured. In all experiments, exponentially growing cells were used. The MM.1R cells $\left(1 \times 10^{5} /\right.$ well $)$ were cultured in growth medium in 96-well plates in triplicate, and incubated with different concentrations of drugs (Table 1).

\section{Assay of MM1.R cell growth inhibition}

The combined effect of curcumin and bortezomib on cell growth was determined using an MTT assay. MM1.R cells $\left(1 \times 10^{5}\right.$ cells $\left./ \mathrm{ml}\right)$ were seeded in 96-well plates and treated with the indicated concentrations of curcumin or bortezomib alone or in combination for $24 \mathrm{~h}$ followed by an MTT assay to measure cell proliferation and viability. Serum free RPMI 1640 was used as untreated group. Concentration groups were set up in triplicate with each well containing $0.2 \mathrm{ml}$ of medium. After $24 \mathrm{~h}, 20 \mu \mathrm{l}$ of MTT working solution (final concentration, 0.5 $\mathrm{mg} / \mathrm{ml}$ ) was added to each well and the cells were incubated in a humidified incubator at $37^{\circ} \mathrm{C}$ under $5 \% \mathrm{CO}^{2}$ for $4 \mathrm{~h}$. After this, the cells were centrifuged at $1,000 \mathrm{rpm}$, the supernatant was carefully aspirated, and $0.2 \mathrm{ml}$ of dimethyl sulfoxide was added to each well. This suspension was shaken until the purple-blue precipitate fully dissolved. The average absorbance $(A)$ across the triplicate wells was read at $570 \mathrm{~nm}$ on a microplate reader. The

Table 1: Curcumin and bortezomib treatment groups

\begin{tabular}{lllllllll}
\hline Group & A & B & C & D & E & F & G & H \\
\hline Curcumin $(\mu \mathrm{g} / \mathrm{ml})$ & 40 & 20 & 10 & 0 & 0 & 10 & 20 & 40 \\
Bortezomib $(0.01 \mathrm{mM})$ & + & + & + & + & - & - & - & -
\end{tabular}


survival rate was calculated according to Eqn 1. Survival rate of the untreated group was taken $100 \%$.

Survival $(\%)=\mathrm{Ea} / \mathrm{Ua} \times 100$

where $\mathrm{Ea}$ is the absorbance of experimental group and $\mathrm{Ua}$ is the absorbance of untreated group.

\section{Assay of MM1.R apoptosis}

A flow cytometry assay was used to detect phosphatidylserine (PS) membrane translocation. MM1.R cells $\left(5 \times 10^{5} / \mathrm{ml}\right)$ were seeded in a $25 \mathrm{~cm}^{2}$ flask and incubated with different concentrations of drugs just as above. Simultaneously, the untreated group was set up. After $16 \mathrm{~h}$, the cells were harvested and resuspended in binding buffer and $100 \mu$ of cell suspension was removed into a FACS tube. Thereafter, $5 \mu$ l of Annexin V (FITC-conjugated) and $5 \mu \mathrm{l}$ of propidium iodide (PI) were added and mixed gently, followed by incubation for $15 \mathrm{~min}$ in the dark at room temperature. Finally, $300 \mu$ of binding buffer was added and the cells were immediately observed under a fluorescence microscope to detect phosphatidylserine (PS) membrane translocation. Cellquest 1.2 analysis software was used to analyze the results.

Assay of MM1.R caspase 3, caspase 9, NF-KB, and HSP90 protein expression

Western blot assays were used to measure protein expression levels. Protein from MM1.R cells in each group was extracted using wholecell protein extraction kit (Active Motif, CA, USA). The total protein concentration of each sample was measured via a Bradford assay (Bradford reagent from Pierce, IL, USA) carried out using a UV/Vis spectrophotometer (Beckman DU640; Beckman Coulter, CA, USA). Equal amounts of MM1.R cell total protein (40 $\mu \mathrm{g} / \mathrm{lane})$ from different groups were loaded onto 100-150 g/L polyacrylamide gel, followed by separation by electrophoresis and transfer to nitrocellulose membranes. The membranes were blocked with Tris-buffered saline (TBS) containing $0.1 \%$ Tween-20 (TBST) and $5 \%$ non-fat milk (50 g/L) for $1 \mathrm{~h}$ at room temperature. After three 5-min washes, they were incubated overnight at $4{ }^{\circ} \mathrm{C}$ with primary antibodies; 1:500 dilution for caspases 3 and 9 and 1:200 for NF-kB, HSP90, and $\beta$-actin. After thorough washing $(5 \min \times 3)$, membranes were incubated with HRP. conjugated secondary antibodies at room temperature for $1 \mathrm{~h}$ with gentle shaking. Finally, membranes were treated with a luminol-based enhanced-chemiluminescence HRP substrate
(Super Signal West Dura Kit; Pierce, IL, USA) and scanned using $X$ film (Kodak, NY, USA) lithography. The film was in turn scanned by a laser densitometer to quantify the protein levels and these were normalized against $\beta$-actin levels.

\section{Statistical analysis}

SPSS 15.0 software was used for statistical analysis of the data, which was expressed as the average \pm SD. Differences between groups were analyzed by one-way analysis of variance (ANOVA). Survival and apoptosis rate are relative to drug concentrations, thus we chose regression analysis to determine the relationship between them. $P<0.05$ was considered statistically significant.

\section{RESULTS}

\section{Growth inhibition by curcumin alone and in combination with with $0.01 \mathrm{mM}$ bortezomib}

MM1.R cells were treated with $0-40 \mu \mathrm{g} / \mathrm{ml}$ doses of curcumin $\left(<\mathrm{IC}_{50}\right)$ for $24 \mathrm{~h}$; the results showed that curcumin alone inhibited the growth of MM1.R cells in a concentration-dependent manner $(R=0.921, p<0.05)$, and the differences between concentration groups were statistically significant $(p<0.05)$. In contrast, $0.01 \mathrm{mM}$ bortezomib alone did not significantly inhibit cell growth $(p>0.05)$. However, when different concentrations of curcumin were combined with bortezomib, the effect was complementary, leading to a further decrease in cell growth (Table 2). The inhibitory effect of bortezomib with 20 or $40 \mu \mathrm{g} / \mathrm{ml}$ curcumin was significantly greater than that of curcumin alone $(p<0.05)$.

\section{Induction of apoptosis by curcumin alone and in combination with $0.01 \mathrm{mM}$ bortezomib}

MM1.R cells were treated with curcumin alone ( 0 - $40 \mu \mathrm{g} / \mathrm{ml}$ ) for $16 \mathrm{~h}$, after which, annexin $V$ binding and propidium iodide staining were determined by flow cytometry. The results showed that curcumin alone could induce MM1.R cell apoptosis in a concentration-dependent manner $(R=0.812, p<0.05)$, and the difference between the concentration groups was statistically significant $(p<0.05)$. On the other hand, we did not observe significant apoptosis mediated by $0.01 \mathrm{mM}$ bortezomib alone $(p>$ $0.05)$. When cells were incubated with $0.01 \mathrm{mM}$ bortezomib and 10,20 , or $40 \mu \mathrm{g} / \mathrm{ml}$ curcumin, the apoptosis rate was increased compared to that for the same curcumin concentrations alone (Table 2 and Figure $1 ; p<0.05$ ). 
Table 2: Growth inhibition by curcumin alone and in combination with $0.01 \mathrm{mM}$ bortezomib

\begin{tabular}{|c|c|c|c|}
\hline Group & $A_{570}$ & Survival rate (\%) & Apoptosis rate (\%) \\
\hline $\begin{array}{l}\mathrm{A} \\
\mathrm{B}\end{array}$ & $\begin{array}{l}0.40 \pm 0.02 \\
0.59 \pm 0.04\end{array}$ & $\begin{array}{l}33.11 \pm 2.32 \# \\
44.87 \pm 2.92 \#\end{array}$ & $\begin{array}{c}40.3 \pm 3.75^{*} \\
25.71 \pm 2.91^{*}\end{array}$ \\
\hline $\mathrm{C}$ & $0.98 \pm 0.07$ & $72.24 \pm 4.31 \#$ & $12.31 \pm 2.04^{*}$ \\
\hline $\mathrm{D}$ & $1.47 \pm 0.04$ & $90.18 \pm 5.96$ & $3.42 \pm 1.32$ \\
\hline$E$ & $1.57 \pm 0.09$ & 100 & $2.35 \pm 1.44$ \\
\hline $\mathrm{F}$ & $1.37 \pm 0.04$ & $70.01 \pm 4.51 \#$ & $3.06 \pm 2.18$ \\
\hline $\begin{array}{l}\mathrm{G} \\
\mathrm{H}\end{array}$ & $\begin{array}{l}0.90 \pm 0.09 \\
0.75 \pm 0.02\end{array}$ & $\begin{array}{l}59.38 \pm 6.49 \# \\
44.58 \pm 5.07 \#\end{array}$ & $\begin{array}{l}10.16 \pm 3.47^{*} \\
16.72 \pm 4.74^{*}\end{array}$ \\
\hline \multicolumn{4}{|c|}{$\begin{array}{l}A=40 \mu \mathrm{g} / \mathrm{ml} \text { curcumin }+0.01 \mathrm{mM} \text { bortezomib; } B=20 \mu \mathrm{g} / \mathrm{ml} \text { curcumin }+0.01 \mathrm{mM} \text { bortezomib; } C=10 \\
\mu \mathrm{g} / \mathrm{ml} \text { curcumin }+0.01 \mathrm{mM} \text { bortezomib; } D=0.01 \mathrm{mM} \text { bortezomib; } E=\text { untreated group; } F=10 \mu \mathrm{g} / \mathrm{ml} \\
\text { curcumin; } \mathrm{G}=20 \mu \mathrm{g} / \mathrm{ml} \text { curcumin; } H=40 \mu \mathrm{g} / \mathrm{ml} \text { curcumin; \# survival rate value is significantly different } \\
(p<0.05) \text { compared to untreated group }(E) .{ }^{*} \text { value is significantly different }(p<0.05) \text { compared to } \\
\text { untreated group (E); } A_{570}=\text { Absorbance at } \lambda \text { of } 570 \mathrm{~nm}\end{array}$} \\
\hline
\end{tabular}

Effect of independent and combination treatments on expression of caspase 3 , caspase 9, NF-KB, and HSP90

Western blot analysis (Figure 2) showed that $0.01 \mathrm{mM}$ bortezomib alone had no significant effect on caspase 3, caspase 9, NF-kB, or HSP90 protein expression in MM1.R cells ( $p>$ $0.05)$; however, curcumin alone $(0-40 \mu \mathrm{g} / \mathrm{ml})$ induced upregulation of caspases 3 and $9(p<$
0.05), which correlated with increased apoptosis. Treatment with curcumin alone reduced NF-KB and HSP-90 expression $(p<0.05)$ and this also correlated with increased apoptosis. Bortezomib combined with curcumin $(10 \mu \mathrm{g} / \mathrm{ml}, 20 \mu \mathrm{g} / \mathrm{ml}$, or $40 \mu \mathrm{g} / \mathrm{ml}$ ) significantly increased expression of caspases 3 and 9 while reducing NF-KB and HSP90 expression in a concentration-dependent manner. The effects of the combined treatment were greater than those of curcumin alone.

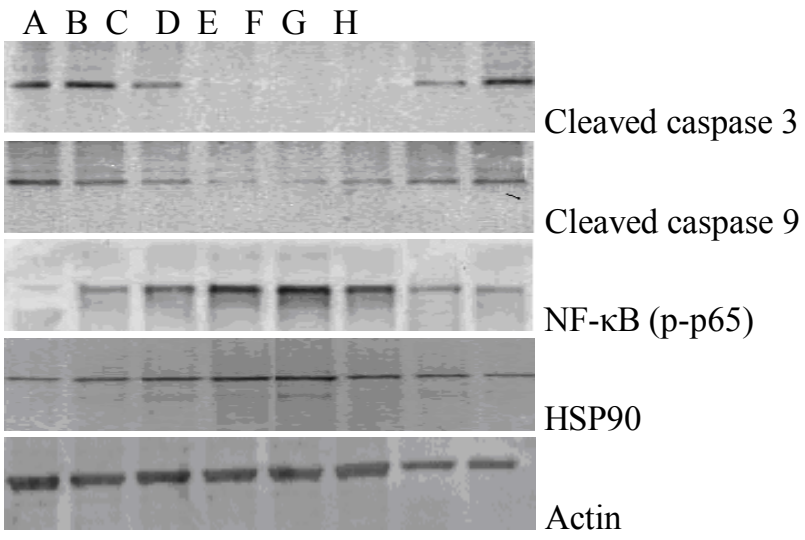

Figure 2: Western blot showing the effect of curcumin (alone or combined with bortezomib) on MM1.R cell caspase 3, caspase 9, NF-KB and HSP90 expression. A-C, the effect of $0.01 \mathrm{mM}$ bortezomib on MM1.R cell caspase 3, caspase $9, \mathrm{NF}-\mathrm{KB}$ and HSP90 expression combined with $40 \mu \mathrm{g} / \mathrm{ml}$ curcumin (A) or $20 \mu \mathrm{g} / \mathrm{ml}$ curcumin (B) or $10 \mu \mathrm{g} / \mathrm{ml}$ curcumin (C); D, the effect of $0.01 \mathrm{mM}$ bortezomib alone on MM1.R cell caspase 3, caspase 9 , NF-KB and HSP90 expression; E, untreated group; F-H, the effect of $10 \mu \mathrm{g} / \mathrm{ml}$ curcumin (F) or $20 \mu \mathrm{g} / \mathrm{ml}$ curcumin (G) or $40 \mu \mathrm{g} / \mathrm{ml}$ curcumin (H) alone on MM1.R cell caspase 3, caspase 9, NF-KB and HSP90 expression. Staining of b-actin served as a loading control. \#, * Value is significantly different $(p<0.05)$ to untreated group $(E)$. 

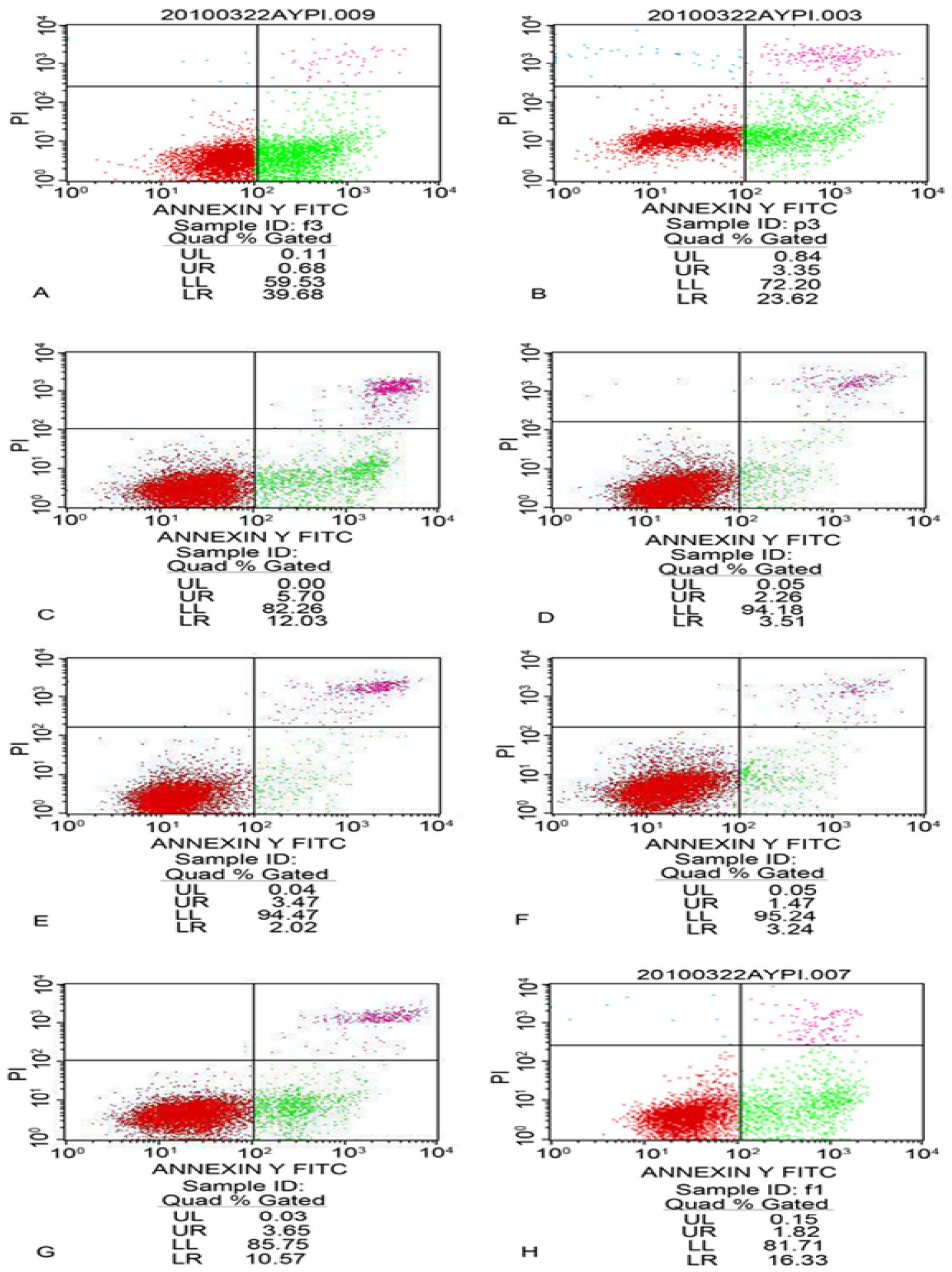

Figure 1: Flow-cytometric analysis of the effect of curcumin alone or combined with bortezomib on myeloma cell (MM1.R) apoptosis. A-C, MM1.R cells were incubated with $0.01 \mathrm{mM}$ bortezomib and $40 \mu \mathrm{g} / \mathrm{ml}$ curcumin $(\mathrm{A})$ or 20 $\mu \mathrm{g} / \mathrm{ml}$ curcumin(B) or $10 \mu \mathrm{g} / \mathrm{ml}$ curcumin; D, MM1.R cells were incubated with $0.01 \mathrm{mM}$ bortezomib alone; $E$, untreated group; F-H, MM1.R cells were treated with $10 \mu \mathrm{g} / \mathrm{ml}$ curcumin (F) or $20 \mu \mathrm{g} / \mathrm{ml}$ curcumin (G) or $40 \mu \mathrm{g} / \mathrm{ml}$ curcumin $(\mathrm{H})$ alone for $16 \mathrm{~h}$. A-D showed us that the combined treatment increased the cell apoptosis rate. E-H indicated that curcumin alone could induce MM1.R cell apoptosis in a concentration-dependent manner. Moreover, the apoptosis rate of combined treatment group was increased compared to that for the same curcumin concentrations alone. \#, ${ }^{*}$ Value is significantly different $(p<0.05)$ to untreated group (E). 


\section{DISCUSSION}

In this study, we investigated whether, and by what mechanism, the addition of curcumin could improve the anti-cancer efficacy of bortezomib treatment in cultured myeloma cells.

Previous studies have revealed that curcumin alone can inhibit tumor proliferation and induce apoptosis of myeloma cells (H929 and RPMI8226 lines) [8]. Our experiments were in agreement, showing that curcumin alone (10 $40 \mu \mathrm{g} / \mathrm{ml}$ ) greatly inhibited cell proliferation (approximately $40 \%$ reduction) and induced apoptosis in MM1.R myeloma cells in a concentration- dependent manner.

We found that a low concentration of bortezomib $(0.01 \mathrm{mM})$ had no significant effect on apoptosis in myeloma cells, but when combined with different concentrations of curcumin, high rates of apoptosis (up to $40.3 \pm 3.75 \%$ ) were induced. These rates were significantly greater than for curcumin alone, thus indicating that the two drugs have a synergistic effect on apoptosis.

A study by Mitsiades et al [9] suggested that bortezomib mediates myeloma cell apoptosis by regulating FASL-FAS expression and caspase pathway activation. The current study showed that treatment with low concentration bortezomib did not significantly increase expression of caspases 3 or 9 , but when combined with curcumin, levels were significantly elevated in accordance with concentration, and this effect was greater than that seen with curcumin alone; again, indicating a synergistic apoptotic effect. A previous study of ours indicated that triptolide (TPL) also upregulates caspase 3 and caspase 9 , and here the same pattern was observed: bortezomib alone had no effect while combination with TPL increased caspase expression in a synergistic and concentrationdependent fashion.

MM cells express highly active NF-KB, and bortezomib inhibits tumor growth mainly by blocking the NF-KB signaling pathway [10]. This study showed that low concentrations of bortezomib did not affect NF-KB expression levels significantly, explaining the absence of both induced apoptosis and inhibition of proliferation. However, when combined with curcumin, the expression of NF-kB was significantly downregulated, therefore, we suggest that bortezomib can enhance the ability of curcumin to block NF-KB signaling, resulting in increased apoptosis and decreased proliferation. Our experiments demonstrated that low concentrations of bortezomib had no significant effect on HSP90 expression whereas curcumin alone reduced it and this effect was enhanced when the treatments were combined; in both cases, the magnitude of the effect corresponded to the curcumin concentration. We conclude that curcumin and bortezomib have a synergistic inhibitory effect on HSP90 expression of MM1.R cells.

Angelo et al [11] have suggested a mechanism that may explain the effect of curcumin on HSP90: curcumin can inhibit the activation of the heat shock response by blocking heat shock transcription factor (HSF1). Thus, curcumin may downregulate HSP90 in human myeloma cells via reduced $\mathrm{mRNA}$ transcription, thereby partially blocking the heat shock response and inducing apoptosis. We also suggest that reducing HSP90 expression through downregulation of the signal transduction protein, NF-kB, enhances the effect of bortezomib, so that a low dose of bortezomib combined with curcumin can induce substantial levels of apoptosis.

\section{CONCLUSION}

Myeloma cell proliferation can activate multiple signaling pathways that result in the emergence of drug resistance in the course of mono-targeted therapies; such pathways include those involving HSP9O and NFKB. We conclude that curcumin significantly enhances the ability of bortezomib to induce apoptosis in myeloma cells by inhibiting HSP90 and NFKB signaling, and that it could therefore play a role in a multi-targeted approach that reduces the occurrence of bortezomib resistance in $\mathrm{MM}$ therapy. Our findings provide a good experimental basis for the clinical application of curcumin in combination with bortezomib.

\section{ACKNOWLEDGEMENT}

The authors thank Professor Yongqing Zhou (State Key Laboratory for Diagnosis and Treatment of Infectious Diseases, First Affiliated Hospital, Zhejiang University College of Medicine, Hangzhou, Zhejiang, PR China) for his assistance. This manuscript was proofread by an English-speaking professional with science background at Elixigen Corporation. This work was supported in part by grants from National Science Fund of China (81172250), the National Science Fund of China (LY12H16015, 2011ZDA008) and the Scientific Foundation of Zhejiang (2012C13021-3). 


\section{REFERENCES}

1. Mosser DD, Morimoto RI. Molecular chaperones and the stress of oncogenesis. Oncogene 2004; 23(16): 2907-2918.

2. Andrulis $M$, Chatterjee $M$, Jain $S$, Stühmer $T$, Ungethüm $U$, Kuban RJ, Lorentz H, Bommert K, Topp M, Kramer $D$, et al. Heat shock protein 90 alpha and beta are overexp ressed in multiple myeloma cells and critically contribute to survival. Verh Dtsch Ges Pathol, 2007; 91(2): 330-337.

3. Solit $D B$, Rosen N. Hsp90: a novel target for cancer therapy. Curr Top Med Chem 2006; 6(11): 12051214.

4. Gertz MA, Ghobrial I, Luc-Harousseau J. Multiple myeloma: biology, standard therapy, and transplant therapy. Biol Blood Marrow Transplant, 2008; 15 (1 Supp I): 46.

5. Ludwig $H$, Khayat D, Giaccone G, Facon T. Proteasome inhibition and its clinical prospects in the treatment of hematologic and solid malignancies. Cancer 2005; 104(9): 1794-1807.
6. Richardson PG, Barlogie B, Berenson J, Singhal S, Jagannath S, Irwin DH, Rajkumar SV, Srkalovic G, Alsina M, Anderson KC. Extended follow-up of a phase II $t$ rial in relapsed, refractory multiple myeloma. Cancer, 2006; 106 (6): 1316-1319.

7. Bai QX, Zhang XY. Curcumin Enhances Cytotoxic Effects of Bortezomib in Human Multiple Myeloma H929 Cells: Potential Roles of NF-KB/JNK. Int J Mol Sci. 2012; 13(4): 4831-4838.

8. Mitsiades N, Mitsiades CS, Poulaki V, Chauhan D, Fanourakis G, Gu X, Bailey C, Joseph M, Libermann $T A$, Treon SP, et al. Molecular sequelae of proteasome inhibition in human multiple myeloma cells (J). Proc NatlAcad SciUSA, 2002; 99 (22): 14374-14379.

9. Adams J. The proteasome: a suitable antineoplastic target. Nat Rev Cancer, 2004; 4(5): 349-360.

10. Angelo LS, Wu JY, Meng F, Sun M, Kopetz S, McCutcheon IE, Slopis JM, Kurzrock R. Combining curcumin (diferuloylmethane) and heat shock protein inhibition for neurofibromatosis 2 treatment: analysis of response and resistance pathways. Mol Cancer Ther. 2011; 10(11): 2094-103. 